\title{
Plasma radiation for atmospheric entry at Titan: Emission spectroscopy measurements and numerical rebuilding
}

\author{
R. SOB BIA ${ }^{1}$, P. LEY LA N D ${ }^{1}$, Y. B A BOU ${ }^{2}$, D. POT TER ${ }^{3}$ and L. MAR R A F F A \\ ${ }^{1}$ Ecole Polytechnique Fédérale de Lausanne (EPFL), EPFL-GR-SCI-STI-IAG, Interdisciplinary Aerodynamics Group, \\ Station 9, CH-1015 Lausanne, Switzerland \\ (penelope.leyland@epfl.ch) \\ ${ }^{2}$ Aeronautics and Aerospace Department, von Karman Institute for Fluid Dynamics, \\ Chaussée de Waterloo 72, 1640 Rhode-Saint-Genèse, Belgium \\ ${ }^{3}$ Centre for Hypersonics, University of Queensland, St Lucia QLD 4072, Australia \\ ${ }^{4}$ Aerothermodynamics Section, ESA/ESTEC, Keplerlaan 1, PO Box 299, 2200AG, Noordwijk, the Netherlands
}

(Received 3 August 2011; revised 20 July 2012; accepted 10 September 2012; first published online 21 January 2013)

\begin{abstract}
Emission spectroscopy measurements on a plasma representative of Titan atmosphere composition were obtained in the Inductively Coupled Plasma wind tunnel facility (VKI-Minitorch) at the von Karman Institute in Belgium. Temperatures ranged from 3600 to $5000 \mathrm{~K}$, pressure was fixed at $300 \mathrm{mbar}$, and the molar composition was $1.9 \% \mathrm{CH}_{4}$ and $98.1 \% \mathrm{~N}_{2}$. The high-pressure plasma was produced to obtain conditions close to equilibrium. In conjunction, line-by-line calculations have been carried out to assess the reliability of two distinct sets of molecular electronic transition moments, recently released, by predicting the radiative signature of high-temperature $\mathrm{N}_{2}-\mathrm{CH}_{4}$ plasma. The radiative transfer problem was solved by considering the plasma plume at local thermodynamic equilibrium conditions in an axisymmetric configuration. Comparisons between the synthetic and experimental spectra demonstrated good agreement for the $\mathrm{CN}$ Violet and high-wavelength $\mathrm{CN}$ Red bands, while some discrepancies were observed for the $\mathrm{C}_{2}$ Swan bands and low-wavelength CN Red bands.
\end{abstract}

\section{Introduction}

During a hypersonic atmospheric entry (for example into Earth, Mars, or Titan), complex heat and mass transfers take place between the plasma surrounding an entering probe or vehicle and its surface (Mitcheltree and Gnoflo 1995; Gupta 2000; Mazoue and Marraffa 2005; Magin et al. 2006; Park 2007; Boyd et al. 2008; da Silva et al. 2009; Potter 2011; Witasse et al. 2011). For a conventional entry along super-orbital trajectory, characterized by elevated speed, typically above $10 \mathrm{~km} / \mathrm{s}$ for Earth re-entry, the non-equilibrium plasma generated behind the bow shock is responsible for a considerable radiative heat flux incident on the wall of the same order of magnitude as the convective heat flux.

The accurate prediction of incident radiative heat load is therefore critical for reducing design margins and mission costs through thermal protection system (TPS) optimization (Baker et al. 2007; Berry et al. 2007; Braun and Manning 2007). Reliable calculations of radiative fluxes and radiative source strengths in atmospheric entry applications necessitate to use accurate spectroscopic databases allowing to calculate high-temperature gas radiative properties over a wide spectral range (Park et al. 1996; Bose et al. 2006; da Silva and Dudeck 2006; Colonna et al. 2007; Panesi et al. 2008).

Also, reliable calculation of radiative properties can be achieved if and only if the population of energy levels participating the radiative processes are well predicted, implying the use of relevant chemical kinetic models for post-shock flow computation (Nelson et al. 1991; Bose et al. 2006; Gökçen 2007; Leyland et al. 2007; Gallis et al. 2010; Savajano et al. 2011). Several works have been devoted to the establishment of spectroscopic databases, including relevant radiative processes for atmospheric applications, the most prominent being the bound-bound transitions of atomic, diatomic, and triatomic species and continuum transitions such as photoionization, photodissociation, and bremsstrahlung radiation (Park 1985; Hartung 1994; Whiting et al. 1996; Fujita and Abe 1997; Kuznetsova and Surzhikov 1999; Chauveau et al. 2002; Laux 2002; Johnston 2006; Passarinho and da Silva 2006; Smith et al. 2006; Babou et al. 2009; Hyun 2009). However, there is still a lack of studies to assess reliability of tabulated data and in particular those for diatomic molecule bound-bound transitions. During Titan atmospheric entry of the Huygens probe, the radiative and the convective incident heat fluxes peak respectively at approximately $300 \mathrm{~W} \mathrm{~cm}^{-2}$ and $45 \mathrm{~W} \mathrm{~cm}^{-2}$ (estimations taken from Olejniczak et al. $(2003,2004)$ for the nominal entry trajectory with a relative velocity of $6.5 \mathrm{~km} \mathrm{~s}^{-1}$ and $16^{\circ}$ angle-of-attack). The incident intensity is mainly due to electronic radiative transitions of $\mathrm{CN}$ diatomic molecules with the $\mathrm{CN}$ Violet $B^{2} \Sigma^{+}-X^{2} \Sigma^{+}$and the $\mathrm{CN}$ red $A^{2} \Pi-X^{2} \Sigma^{+}$systems 


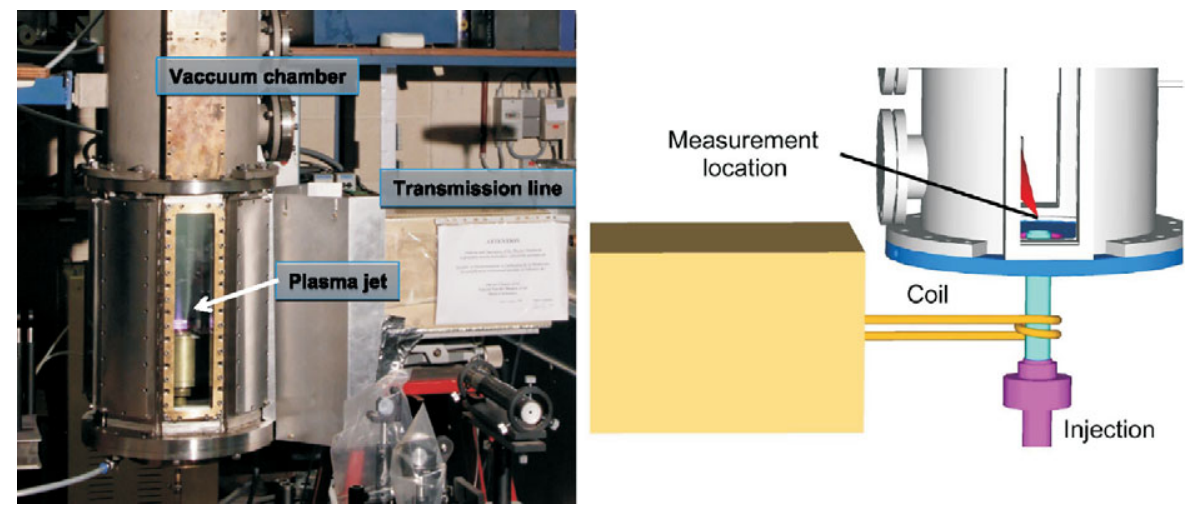

Figure 1. (Colour online) VKI-Minitorch scheme (left). Photograph of VKI-Minitorch air plasma jet.

contributing respectively in the ultraviolet and the visible- and near-infrared spectral domains. Also, in the visible spectral range, the $\mathrm{C}_{2}$ Swan system can contribute in a lesser extent to the plasma emission (Olejniczak et al. 2003, 2004; Wright et al. 2004; Mazoue and Marraffa 2005; Osawa et al. 2006, 2008).

The present study is aimed to assess the reliability of two sets of diatomic electronic transition moments, recently released, to predict the radiative signature of high-temperature $\mathrm{N}_{2}-\mathrm{CH}_{4}$ plasma. The proposed validation task is carried out by means of quantitative comparisons between suiTable experimental emission spectra measured in a thermal plasma jet and spectra simulated on the basis of data taken from Hyun (2009) and from Babou et al. (2009).

A brief outline of experiments, comprehensively described in Playez et al. (2004), is presented in Section 2, and the approach adopted to rebuilt measured spectra is presented in Section 3. In Section 4, comparisons between rebuilt and experimental spectra and discrepancies are discussed.

\section{Experimental}

\subsection{Facility}

The experimental emission spectra considered in this study, taken from Playez et al. (2004), have been obtained by means of optical emission spectroscopy (OES) to determine the absolute intensity emitted by $98.1 \%$ $\mathrm{N}_{2}-1.9 \% \mathrm{CH}_{4}$ plasma. The experiments were conducted in the VKI-Minitorch facility, which is a small-scale high enthalpy plasma jet facility installed at the von Karman Institute. The VKI-Minitorch facility, illustrated in Fig. 1, uses a radio frequency (RF) power generator operating at a frequnecy of $27 \mathrm{MHz}$ to feed a coil inductor surrounding a quartz tube with up to several kilowatts at nominal operating conditions. The RF cylindrical discharge is generated inside the quartz tube of $30 \mathrm{~mm}$ inner diameter and exhausted into a chamber of $300 \mathrm{~mm}$ inner diameter, where a pressure from one atmosphere to few millibar can be maintained. The VKI-Minitorch operating conditions have been se- lected to ensure a reasonable level of jet instabilities to have a relatively laminar jet and a sufficiently high pressure (typically above 100 mbar) to achieve local thermodynamic equilibrium (LTE). In the experiments, documented in Playez et al. (2004) and considered within the present study, $98.1 \% \quad \mathrm{~N}_{2}-1.9 \% \mathrm{CH}_{4}$ mixture is injected into the ICP torch through an annular injection at $0.6 \mathrm{~g} \mathrm{~s}^{-1}$ mass flow rate. The operating power was set to $3.75 \mathrm{~kW}$ and the chamber pressure was maintained at 300 mbar.

\subsection{Test conditions}

The line-of-sight (LOS) plasma jet emission was collected by a set of UV-enhanced aluminum mirrors before being focused in the entrance of an optical fiber connected to a Ocean Optics HR2000-UVIR spectrometer allowing to record in one scan the optical emission in the spectral range $200 \leqslant \lambda \leqslant 110 \mathrm{~nm}$ with a resolution of $1.1 \mathrm{~nm}$. Radial distribution of the plasma jet emission has been measured at few centimeters downstream the outlet by means of a radial scanning of line-of-sight intensity to rebuilt local emission spectra. The axial symmetry of the plasma jet has been assessed. Details on the adopted optical arrangement and its calibration procedure in absolute units can be found in Playez et al. (2004). Before performing the plasma characterization in terms of temperature, the local emission (in $\mathrm{W} \mathrm{cm}{ }^{-3} \mathrm{~nm}^{-1} \mathrm{sr}^{-1}$ ) has been rebuilt by means of an Abel transform applied to measured line-of-sight intensity radial profiles (in $\mathrm{W} \mathrm{cm}^{-2} \mathrm{~nm}^{-1} \mathrm{sr}^{-1}$ ). The local emission spectra considered in the following have been corrected consistently with recommendations of Playez et al. (2004) accounting for calibration uncertainty and plume fluctuations. The temperature was determined through a common fitting approach consisting in the determination of the temperature minimizing the error between the experimental spectrum and spectra simulated at LTE. The procedure was applied to emission spectra recorded in the visible spectral range since the $\mathrm{CN}$ Violet bands in the range $350 \leqslant \lambda \leqslant 430 \mathrm{~nm}$ are self-absorbed, as will be demonstrated in Section 4. The resulting temperature profile is given in Fig. 2. 


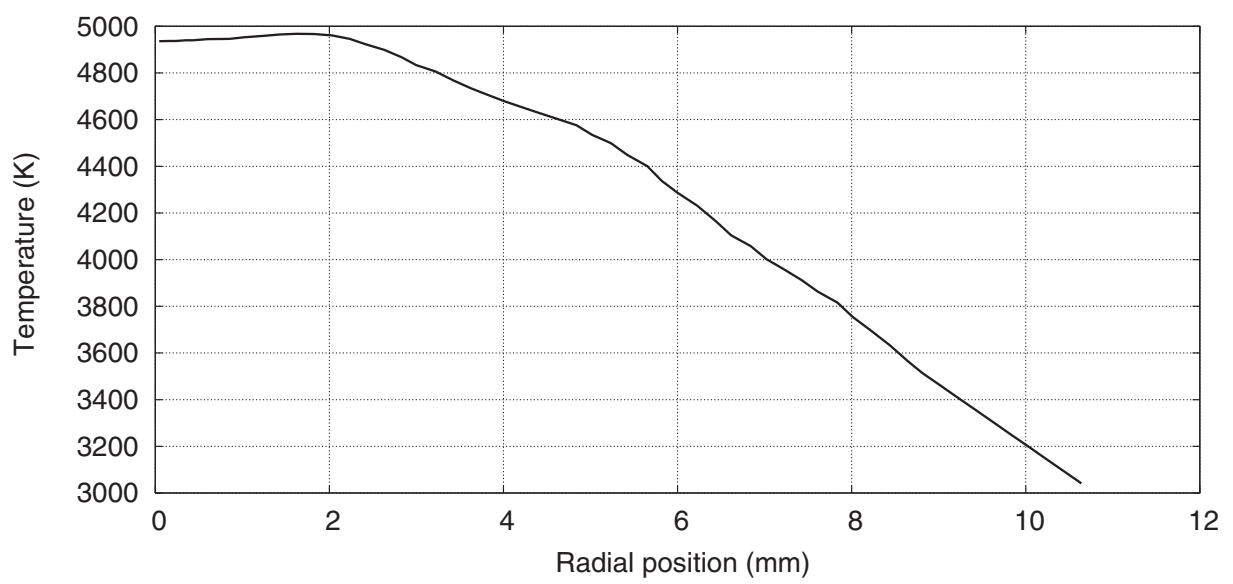

Figure 2. Temperature radial profile taken from Playez et al. (2004) obtained for $98.1 \% \mathrm{~N}_{2}-1.9 \% \mathrm{CH}_{4}$ plasma.

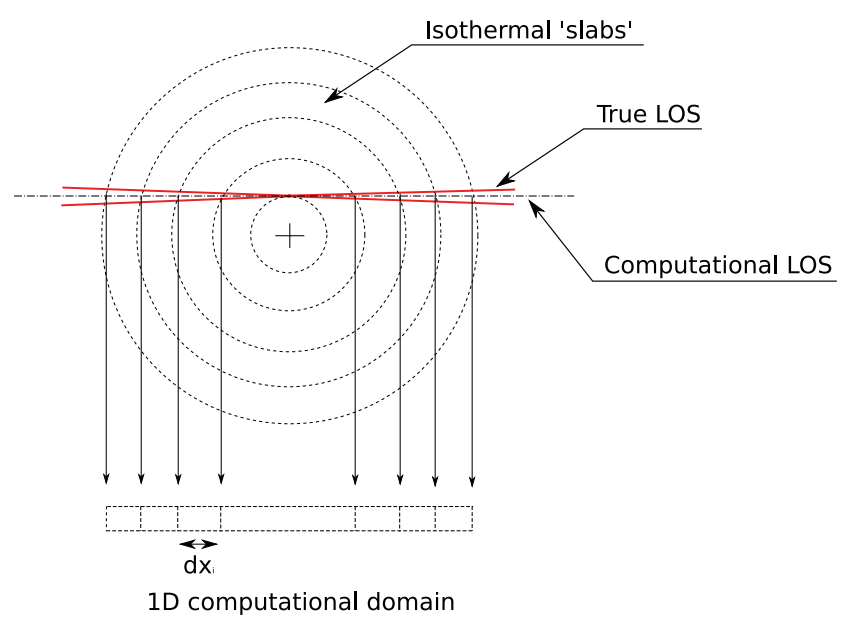

Figure 3. (Colour online) Extraction of a one-dimensional computational domain from the axisymmetric plume for line-of-sight (LOS) calculations.

\section{Simulation}

\subsection{Radiative transfer under local thermochemical equi- librium}

As described in Section 2, the measurements were performed at spatial locations where the plasma is in LTE. A one-dimensional (1D) computational domain is derived from the axisymmetric geometry of the plasma plume, as shown in Fig. 3. The assumption of a onedimensional computational domain is sufficient for the line-of-sight calculations as the effective emission collection volume of the spectrometer is approximately equivalent to a cylinder of diameter $320 \mu \mathrm{m}$ or $1 \%$ of the plume diameter (Playez et al. 2004). The determination of the monochromatic spectral intensity, $I_{\lambda}$, was performed by solving the radiative transport equation (Modest 2003):

$$
\frac{d I_{v}}{d x}=\varepsilon_{v}-\kappa_{v} I_{v},
$$

where $\varepsilon_{\lambda}$ is the monochromatic spectral emission coefficient and $\kappa_{\lambda}$ is the monochromatic spectral absorption coefficient corrected for stimulated emission. The plasma can be represented by $n$ isothermal slabs, where the accuracy of the calculation is improved with an increasing number of slabs. In the present work 101 slabs were found to give adequate results. For this collection of slabs, the monochromatic spectral intensity can be written as

$$
I_{v, n}=\frac{\varepsilon_{v, n}}{\kappa_{v, n}}\left[1-\exp \left(\kappa_{v, n} \Delta x\right)\right]+I_{v, n-1} \exp \left(\kappa_{v, n} \Delta x\right),
$$

where $\Delta x$ is the spatial width along the computational line-of-sight for the $i$ th slab. The plasma was supposed to have a radial extent as presented in Fig. 2, where the temperature radial profile was determined using LTE approximation. A spectral grid formed in frequency space with an average of 1000 points-per-nm has been selected to adequately resolve rovibrational lines.

\subsection{Spectral radiation coefficients}

The line-by-line spectral radiation model developed by Potter (2011) has been used in the present work. The spectral emission and absorption coefficients for an individual rovibrobic diatomic bound-bound transition are respectively calculated (Zel'dovich et al. 1966) as

$$
\varepsilon_{v, u l}=\frac{n_{u} h v_{u l} A_{u l}}{4 \pi} b_{u l}(v)
$$

and

$$
\kappa_{v, u l}=\left(n_{l} \frac{g_{u}}{g_{l}}-n_{u}\right) \frac{c^{2}}{8 \pi v_{u l}^{2}} A_{u l} b_{u l}(v),
$$

where $l$ and $u$ denote the lower and upper rovibronic levels, $n$ is the level number density, $A_{u l}$ is the Einstein coefficient for spontaneous emission (transition probability), $b_{u l}(v)$ is the spectral distribution function, and $g$ is the total degeneracy of particular level. The purpose of the present work is to assess the influence of the transition probability parameter $A_{u l}$ on the resulting spectra. The reader is referred to Potter (2011) for a complete description of spectral radiation calculation.

The CEA code (McBride and Gordon 1996) was used to calculate the equilibrium species densities imposed as initial conditions to the test conditions described in Section 2.2. The species considered were those from Gökçen's (2007) reduced model without $\mathrm{Ar}$ species: $\mathrm{HCN}, \mathrm{C}_{2}, \mathrm{C}, \mathrm{N}_{2}, \mathrm{~N}, \mathrm{CH}, \mathrm{H}, \mathrm{CN}, \mathrm{CH}_{4}, \mathrm{CH}_{3}, \mathrm{CH}_{2}$, 
Table 1. Diatomic radiator systems with transitions considered in this work.

\begin{tabular}{|c|c|c|c|}
\hline Diatomic species & System name & Transition designation & Reference \\
\hline \multirow[t]{7}{*}{$\mathrm{C}_{2}$} & Philips & $A^{2} \Pi_{u}-X^{1} \Sigma_{g}^{+}$ & $\begin{array}{l}\text { Babou et al. (2009), } \\
\text { Hyun (2009) }\end{array}$ \\
\hline & Mulliken & $D^{2} \Sigma_{u}^{+}-X^{1} \Sigma_{g}^{+}$ & $\begin{array}{l}\text { Babou et al. (2009), } \\
\text { Hyun (2009) }\end{array}$ \\
\hline & Deslandres-d'Azambuja & $C^{1} \Pi_{g}-A^{1} \Sigma_{u}$ & $\begin{array}{l}\text { Babou et al. (2009), } \\
\text { Hyun (2009) }\end{array}$ \\
\hline & Ballik-Ramsay & $b^{3} \Sigma_{g}^{-}-a^{3} \Pi_{u}$ & $\begin{array}{l}\text { Babou et al. (2009), } \\
\text { Hyun (2009) }\end{array}$ \\
\hline & Swan & $d^{3} \Pi_{g}-a^{3} \Pi_{u}$ & $\begin{array}{l}\text { Babou et al. (2009), } \\
\text { da Silva and Dudeck (2006) }\end{array}$ \\
\hline & Fox-Herzberg & $e^{3} \Pi_{g}-a^{3} \Pi_{u}$ & $\begin{array}{l}\text { Babou et al. (2009), } \\
\text { Hyun (2009) }\end{array}$ \\
\hline & Freymark & $E^{3} \Sigma_{g}^{+}-A^{1} \Pi_{u}$ & $\begin{array}{l}\text { Babou et al. (2009), } \\
\text { Hyun (2009) }\end{array}$ \\
\hline \multirow[t]{7}{*}{$\mathrm{N}_{2}$} & First-Positive & $B^{3} \Pi_{g}-A^{3} \Sigma_{u}^{+}$ & $\begin{array}{l}\text { Babou et al. (2009), } \\
\text { Hyun (2009) }\end{array}$ \\
\hline & Second-Positive & $C^{3} \Pi_{u}-B^{3} \Pi_{g}$ & $\begin{array}{l}\text { Babou et al. (2009), } \\
\text { Hyun (2009) }\end{array}$ \\
\hline & Hopfield-Birge 1 & $b^{1} \Pi_{u}-X^{1} \Sigma_{g}^{+}$ & $\begin{array}{l}\text { Babou et al. (2009), } \\
\text { Hyun (2009) }\end{array}$ \\
\hline & Hopfield-Birge 2 & $b^{\prime 1} \Pi_{u}-X^{1} \Sigma_{g}^{+}$ & $\begin{array}{l}\text { Babou et al. (2009), } \\
\text { Hyun (2009) }\end{array}$ \\
\hline & Carroll-Yoshino & $c_{4}^{\prime 1} \Sigma_{u}^{+}-X^{1} \Sigma_{g}^{+}$ & $\begin{array}{l}\text { Babou et al. (2009), } \\
\text { Hyun (2009) }\end{array}$ \\
\hline & Worley-Jenkins & $c_{3}^{1} \Pi_{u}-X^{1} \Sigma_{g}^{+}$ & $\begin{array}{l}\text { Babou et al. (2009), } \\
\text { Hyun (2009) }\end{array}$ \\
\hline & Worley & $a_{3}^{1} \Pi_{u}-X^{1} \Sigma_{g}^{+}$ & $\begin{array}{l}\text { Babou et al. (2009), } \\
\text { Hyun (2009) }\end{array}$ \\
\hline \multirow[t]{2}{*}{$\mathrm{CN}$} & Red & $A^{2} \Pi_{i}-X^{2} \Sigma^{+}$ & $\begin{array}{l}\text { Babou et al. (2009), } \\
\text { Hyun (2009) }\end{array}$ \\
\hline & Violet & $B^{2} \Sigma^{+}-X^{2} \Sigma^{+}$ & $\begin{array}{l}\text { Babou et al. (2009) } \\
\text { Hyun (2009) }\end{array}$ \\
\hline
\end{tabular}

$\mathrm{NH}, \mathrm{H}_{2}, \mathrm{CN}^{+}, \mathrm{N}^{+}, \mathrm{N}_{2}^{+}, \mathrm{C}^{+}, \mathrm{H}^{+}$, and $\mathrm{e}^{-}$. The diatomic species, $\mathrm{C}_{2}, \mathrm{CN}$, and $\mathrm{N}_{2}$, were assumed to be the main radiators. The free electrons were included to account for the Stark broadening of species rotational lines due to the presence of ions; however, due to the relatively low plasma temperature the magnitude of Stark broadening was weak. For the $\mathrm{C}_{2}$ species the Freymark's, Mulliken's, Swan's, Deslandres-d'Azambuja's, Philips', Fox-Herzberg's, and Ballik-Ramsay's transitions were included in the calculation. For the $\mathrm{CN}$ species the Red and Violet transitions and for the $\mathrm{N}_{2}$ species the Hopfield-Birge's one and two, Worley's and WorleyJenkin's, First Positive, Second Positive, and CarrollYoshino's transitions were considered. All spectroscopic constants for molecules were obtained from Huber and Herzberg (2010), while the transition probabilities were compiled either from the database of the SPRADIAN07 program from Hyun (2009) or Babou et al. (2009). Updated values for the vibronic transition moments of $\mathrm{C}_{2}$ Swan data in the case of SPRADIAN07 database were taken from da Silva and Dudeck (2006). The $B^{2} \Sigma^{+}-X^{2} \Sigma^{+}(\mathrm{CN}$ violet system) transition was modelled via Hund's case (b) considering spin splitting, $A^{2} \Pi-X^{2} \Sigma^{+}(\mathrm{CN}$ red system) transition was modelled via intermediate Hund's (a)-(b) case considering spin splitting using the Hönl-London factors of Arnold et al. (1969), and the remaining transitions were modelled via Hund's case (a) without spin splitting. In Table 1 the diatomic radiator systems along with the transitions considered in this work are listed.

The emission and absorption coefficients were spectrally distributed with the Voigt profile. The Lorentziantype mechanisms considered are pressure, Stark and natural broadening. Doppler broadening accounts for the Gaussian-type mechanism. A value of $11 \AA$ full width at half maximum has been applied to all spectra, which accounts for the apparatus function of the optical system (Playez et al. 2004).

\section{Results and comparison with experiments}

Comparisons of the numerical rebuilding with experimental emission spectra taken from Playez et al. (2004) are presented in this section. In Figs. 4-6 the comparisons of the measured and computed emissivities using the transition probabilities of Babou et al. (2009) are shown for specific radial positions at $1.24,3.82$, and $8.43 \mathrm{~mm}$ respectively. The numerical results reproduce almost all experimentally observed spectral features with good agreement, an exception being slight underprediction 

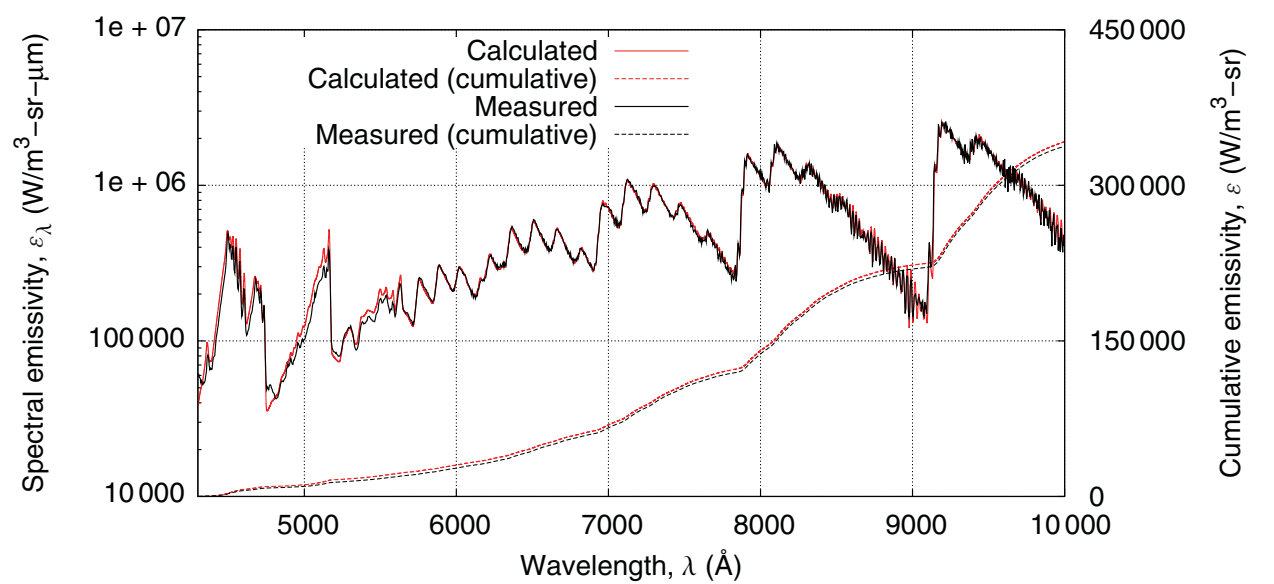

Figure 4. (Colour online) Comparison of the measured and computed emissivities between 4300 and $10000 \AA$ at radial position equal to $1.24 \mathrm{~mm}$ using the transition probabilities of Babou et al. (2009).
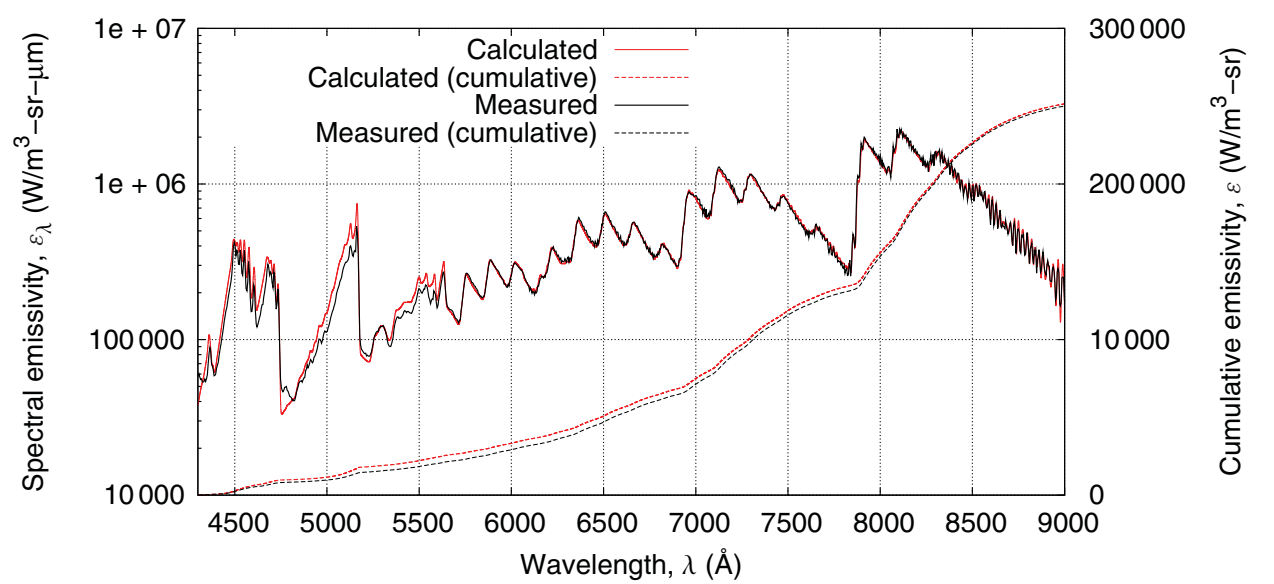

Figure 5. (Colour online) Comparison of the measured and computed emissivities between 4300 and $9000 \AA$ at radial position equal to $3.82 \mathrm{~mm}$ using the transition probabilities of Babou et al. (2009).

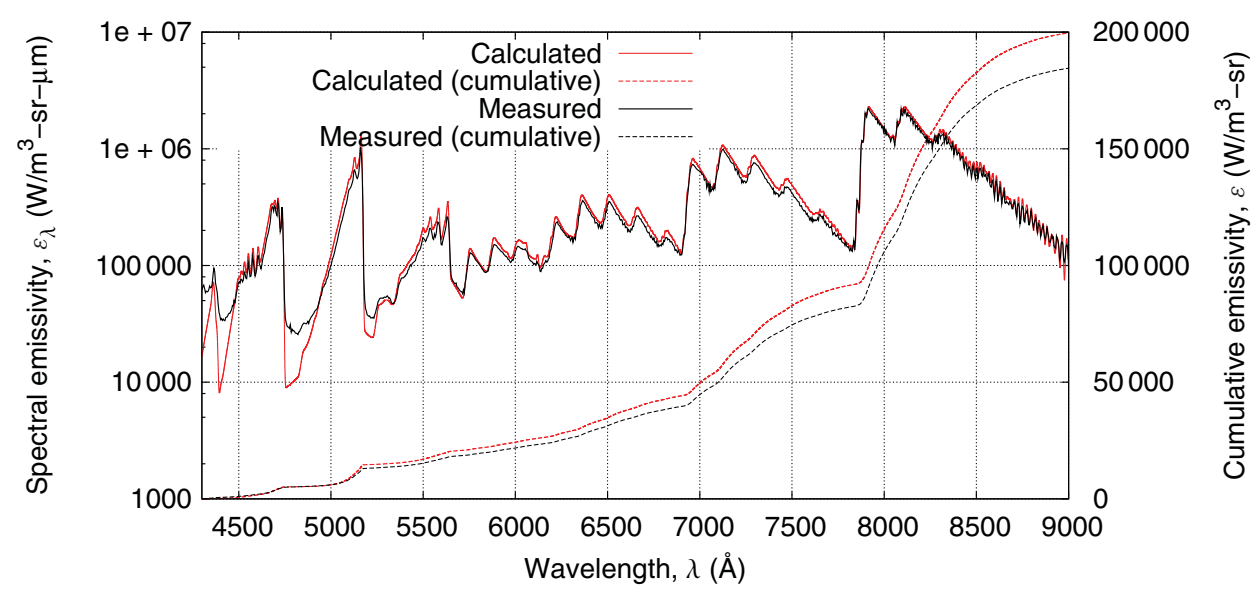

Figure 6. (Colour online) Comparison of the measured and computed emissivities between 4300 and $9000 \AA$ at radial position equal to $8.43 \mathrm{~mm}$ using the transition probabilities of Babou et al. (2009).

of spectral features at approximately 4400, 4800, and $5200 \AA$ where the $\mathrm{C}_{2}$ Swan band system dominates. It is also noted that the magnitude of the discrepancy increases for the measurements toward the edge of the plasma plume where uncertainty raises consequently to the drop of the emission and then the elevation of the signal-to-noise ratio.

In Figs. 7-9 the results for the same calculations presented in Figs. 4-6 are illustrated using the transition probabilities of Hyun (2009). While good agreement 

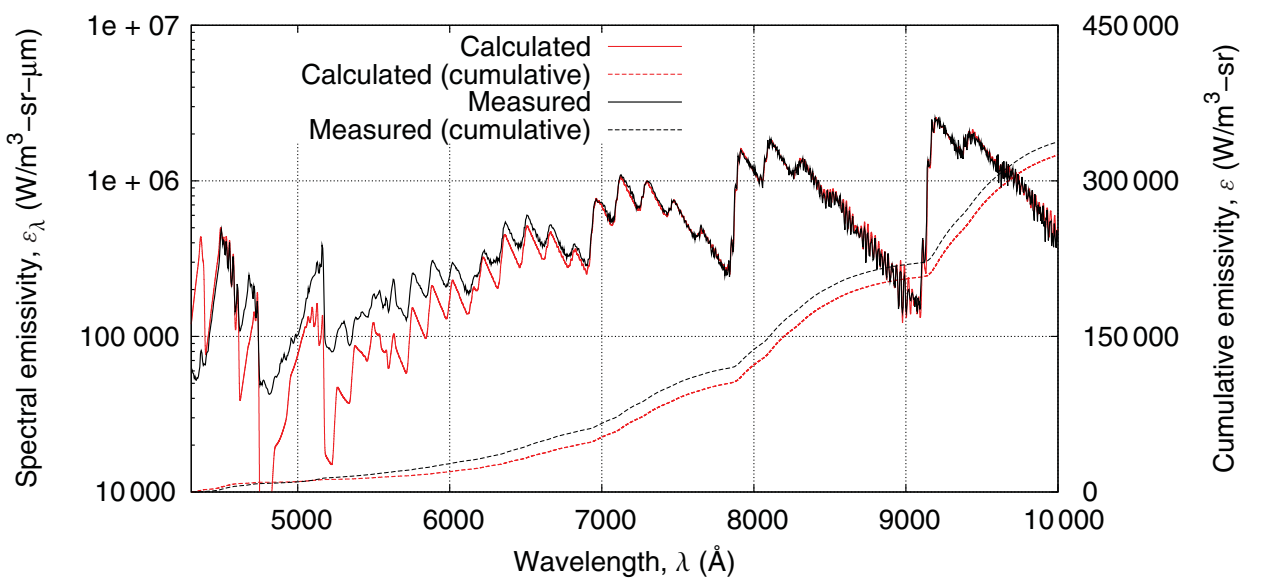

Figure 7. (Colour online) Comparison of the measured and computed emissivities between 4300 and $10000 \AA$ at radial position equal to $1.24 \mathrm{~mm}$ using the transition probabilities of Hyun (2009).
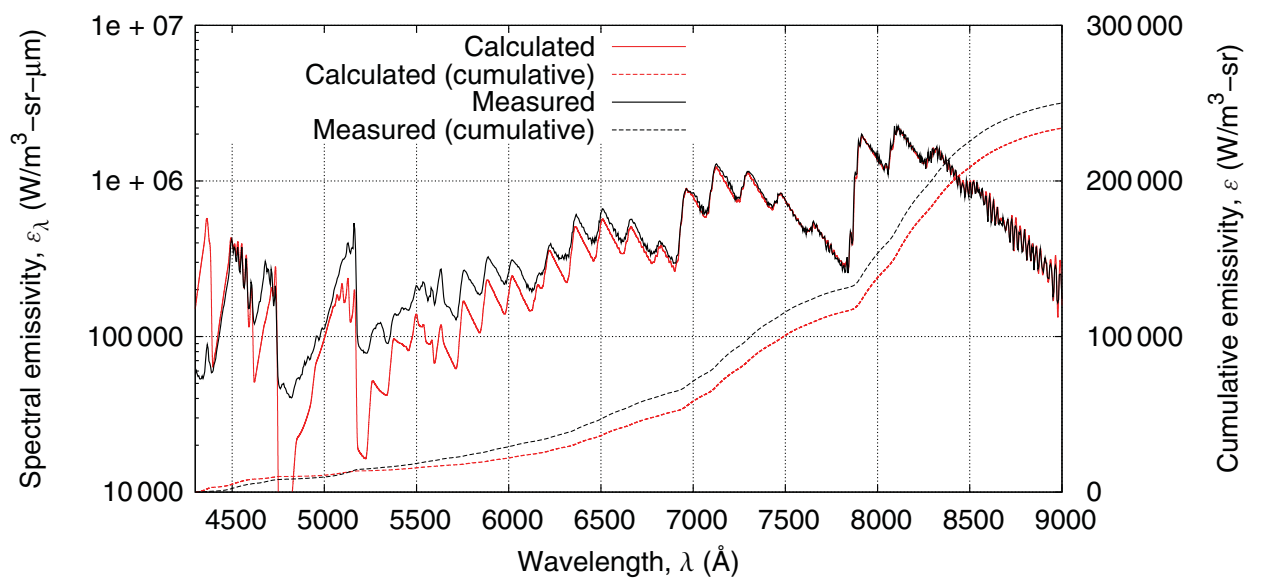

Figure 8. (Colour online) Comparison of the measured and computed emissivities between 4300 and $9000 \AA$ at radial position equal to $3.82 \mathrm{~mm}$ using the transition probabilities of Hyun (2009).

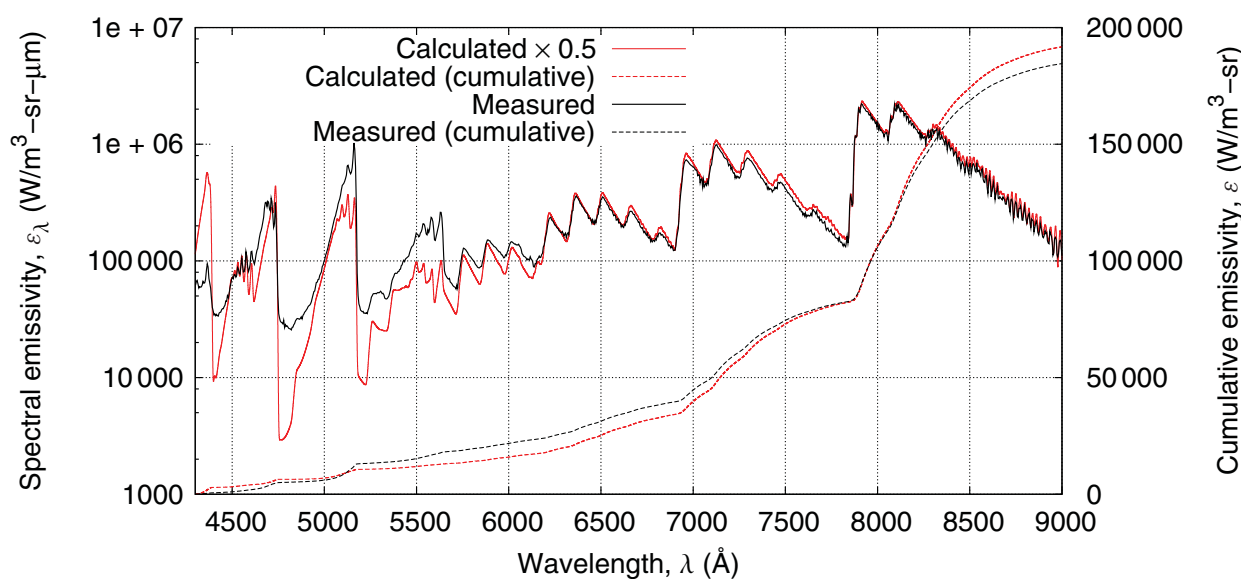

Figure 9. (Colour online) Comparison of the measured and computed emissivities between 4300 and $9000 \AA$ at radial position equal to $8.43 \mathrm{~mm}$ using the transition probabilities of Hyun (2009).

between experimental and numerical spectra is observed for the CN Violet $\Delta v=-2$ manifold at approximately $4600 \AA$ and the CN Red system for $\lambda \geqslant 6500 \AA$, considerable discrepancy exists for the $\mathrm{C}_{2}$ Swan band heads at approximately 4300, 4600, 5100, and $5600 \AA$ and the CN Red system for $\lambda \leqslant 6500 \AA$. In addition, the underprediction of the spectral features at approximately 4400, 4800, and $5200 \AA$ Abserved for the Babou dataset is amplified. A possible contributing factor to the differences observed between the two transition probability datasets is that Babou et al. (2009) consider vibronic transitions with much higher vibrational quantum 


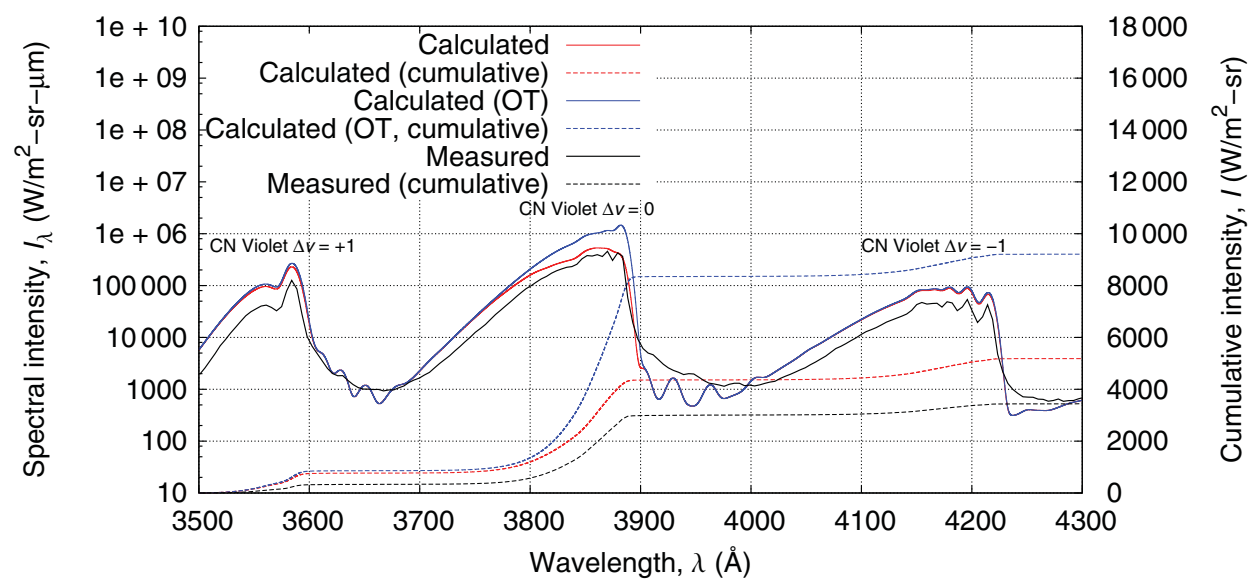

Figure 10. (Colour online) Comparison of the measured and computed monochromatic spectral intensities at the center of the plasma jet using the transition probabilities of Babou et al. (2009). Optically thin (OT) and absorbing plasmas were considered in the spectral range $3500 \leqslant \lambda \leqslant 4300 \AA$.

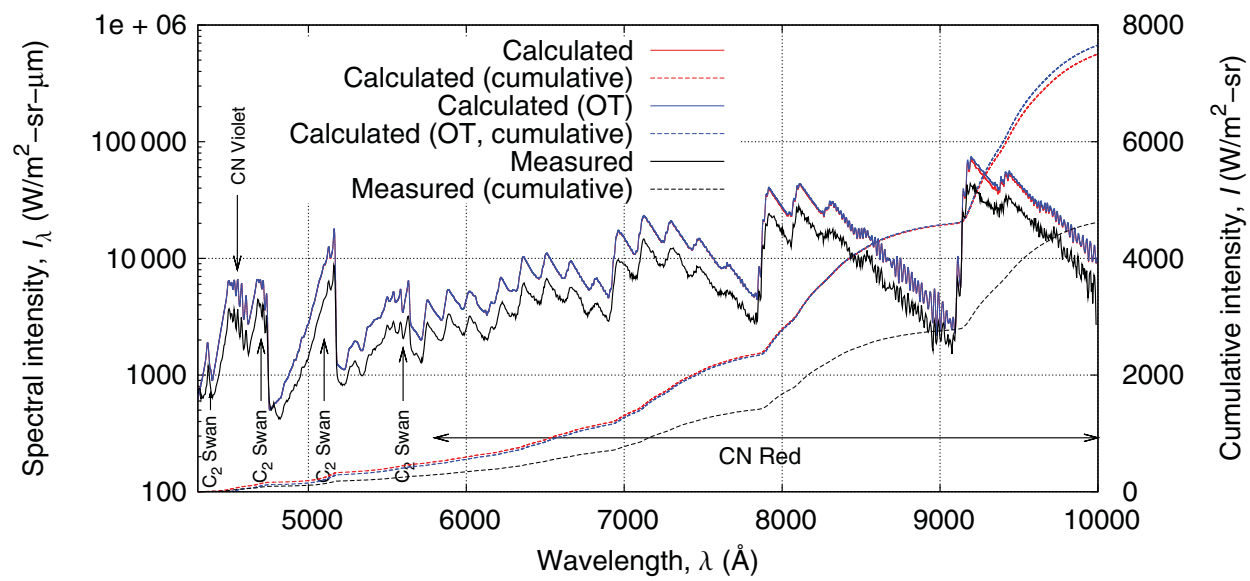

Figure 11. (Colour online) Comparison of the measured and computed monochromatic spectral intensities at the center of the plasma jet using the transition probabilities of Babou et al. (2009). Optically thin (OT) and absorbing plasmas were considered in the spectral range $4300 \leqslant \lambda \leqslant 10000 \AA$.

numbers comapred to Hyun (2009). For example, for the $\mathrm{C}_{2}$ Swan system, Babou et al. (2009) consider $v_{u} \leqslant 18$ and $v_{l} \leqslant 33$, while Hyun (2009) considers $v_{u} \leqslant 10$ and $v_{l} \leqslant 9$. The absence of transitions from elevated vibrational states may explain the underprediction of certain spectral features by the Hyun (2009) dataset, but the overprediction of the $\mathrm{C}_{2}$ Swan bands at approximately $4300 \AA$, for example, also indicates differences in the magnitude of the transition moments for vibrational transitions considered by both datasets.

In Figs. 10 and 11, the spectral intensities at the center of the plasma jet are evinced. The calculated results for both optically thick and optically thin plasmas are presented and the main molecular band systems have been labelled. The omission of absorption results is almost a doubling of the cumulative intensity in Fig. 10, and essentially the same cumulative intensity in Fig. 11. This confirms that the plasma exhibits strong self-absorption in the $3500 \leqslant \lambda \leqslant 4300 \AA$ spec- tral range and negligible self-absorption in the $4300 \leqslant$ $\lambda \leqslant 10000 \AA$ spectral range. While the calculated and measured spectral intensities exhibit good qualitative agreement for the Babou dataset, the calculation consistently overpredicts the experiment by approximately $40 \%$. This difference can be reasonably attributed to the experimental uncertainties (see Figs. 4-6).

The same numerical calculations as in Figs. 10 and 11 have been performed using the transition probabilities of Hyun (2009) in the range $3500-4300 \AA$ and 4300-10000 $\AA$ and these are presented, respectively, in Figs. 12 and 13. Similar observations regarding the selfabsorption qualities of the plasma can be made as for the Babou dataset. Despite the clear discrepancies in the $4300 \leqslant \lambda \leqslant 6000$ spectral range when using the Hyun dataset, the cumulative intensity is essentially the same as for the Babou dataset, indicating that these spectral features are not large contributors to the total radiative flux at these conditions. 


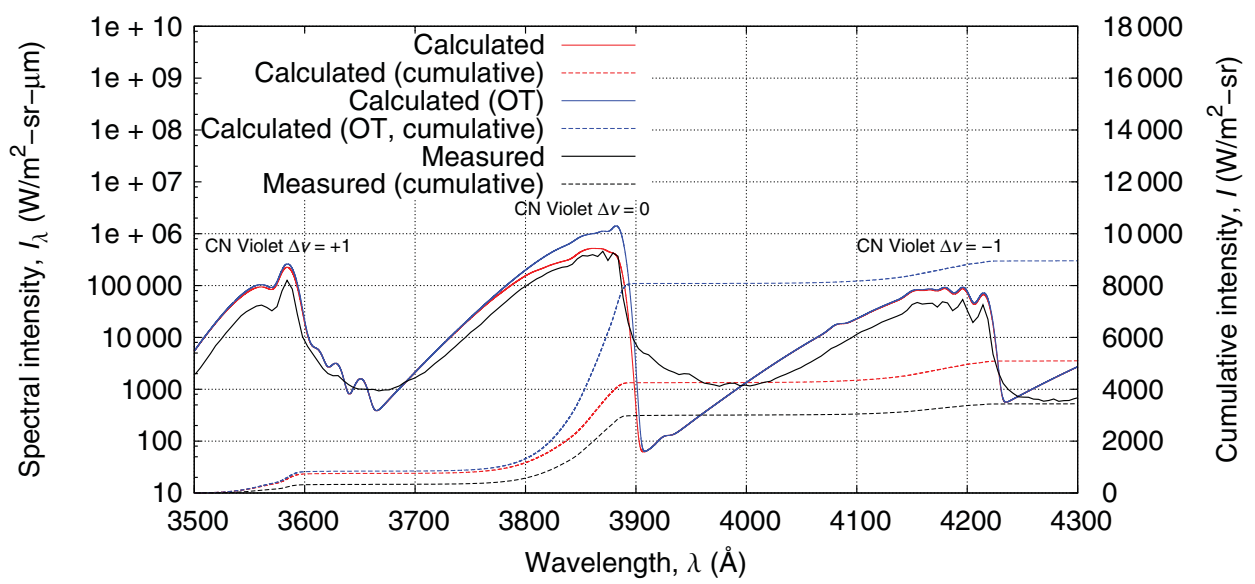

Figure 12. (Colour online) Comparison of the measured and computed monochromatic spectral intensities at the center of the plasma jet using the transition probabilities of Hyun (2009). Optically thin and thick plasmas were considered in the spectral range $3500 \leqslant \lambda \leqslant 4300 \AA$.
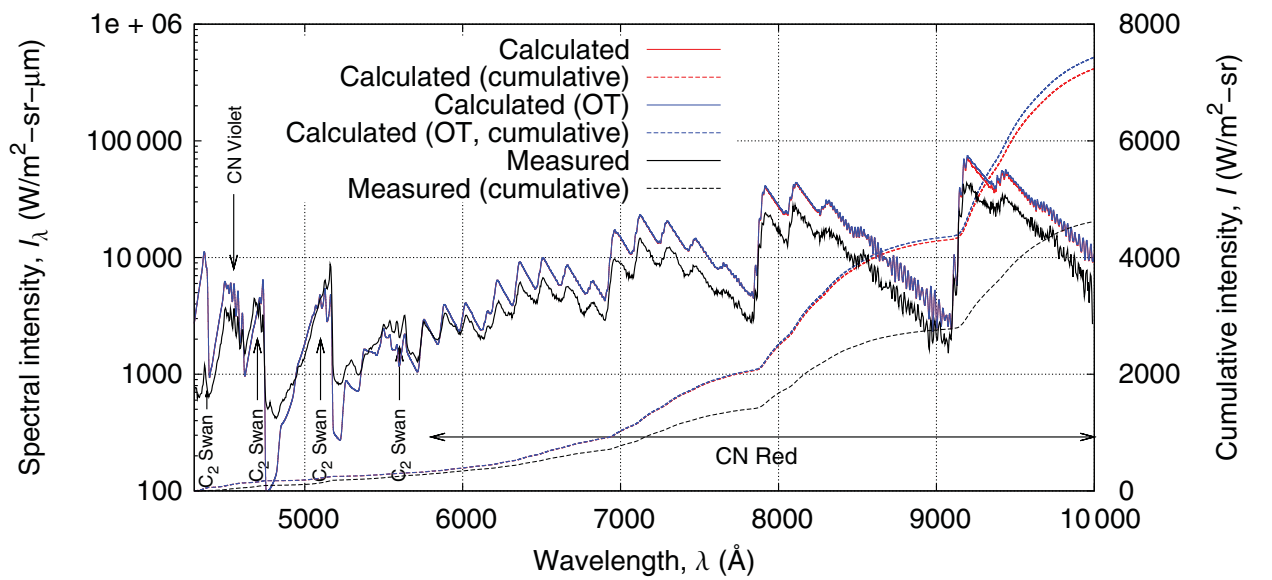

Figure 13. (Colour online) Comparison of the measured and computed monochromatic spectral intensities at the center of the plasma jet using the transition probabilities of Hyun (2009). Optically thin and thick plasmas were considered in the spectral range $4300 \leqslant \lambda \leqslant 10000 \AA$.

\section{Concluding remarks}

Numerical simulations have been performed on data measured in the VKI-Minitorch facility for $\mathrm{CH}_{4}-\mathrm{N}_{2}$ plasma using the line-by-line approach to assess the reliability of two distinct spectroscopic databases, i.e. Hyun (2009) and Babou et al. (2009). The experiment was performed at high pressure (300 mbar) to reach the equilibrium conditions in an axisymmetric configuration. The radiative transport problem was solved with two sets of molecular transition probabilities with $\mathrm{C}_{2}, \mathrm{CN}$, and $\mathrm{N}_{2}$ as main radiators. Between 3500 and $4300 \AA$, the plasma has been found to manifest strong selfabsorption with $\mathrm{CN}$ violet $(\Delta v=0, \pm 1)$ as the main radiation mechanism. Between 4300 and $10000 \AA$, the plasma is essentially optically thin with most of the emission coming from $\mathrm{CN}$ Red, with minor contributions from $\mathrm{C}_{2}$ Swan and $\mathrm{CN}$ violet toward the visible region of this spectral range. While both datasets exhibit good qualitative agreement with experiment for the $\mathrm{CN}$ Violet bands and the higher wavelength $\mathrm{CN}$ Red bands, considerable improvement was found when using the Babou dataset for the $\mathrm{C}_{2}$ Swan bands and lower wavelength $\mathrm{CN}$ Red bands. The results of the comparison suggest that the Babou dataset is more accurate of the two for the conditions at hand, partly because of the wider range of vibronic transitions considered. Nevertheless, the predicted integrated intensity is essentially the same for the two datasets, as the $\mathrm{CN}$ Violet and high-wavelength $\mathrm{CN}$ Red bands contribute the majority of the radiative flux.

\section{Acknowledgements}

This work was a successful collaboration of leading Institutes in the fields of Non-equilibrium Plasma Modelling and Radiation Transport. One of the authors, Raffaello Sobbia, would like to thank the ESA NPI project (Contract no. 20920 CCN1-NPI no. 20930) and 
the Swiss National Science Foundation (Project no. 200021-125225) for financial support.

\section{References}

Arnold, J. O., Whiting, E. E. and Lyle, G. C. 1969 Line by line calculation of spectra from diatomic molecules and atoms assuming a Voigt line profile. J. Quant. Spectrosc. Radiat. Transfer 9, 775-798.

Babou, Y., Rivière, P., Perrin, M.-Y. and Soufiani, A. 2009 Spectroscopic data for the prediction of radiative transfer in $\mathrm{CO}_{2}-\mathrm{N}_{2}$. J. Quant. Spectrosc. Radiat. Transfer 110, 89108.

Baker, Myles L., Huang, J., Riggins, David W. and Camberos, José A. 2007 Second-law methods for the analysis \& design of hypersonic vehicles. Proceedings of the 39th AIAA Thermophysics Conference, Miami, FL, June 2528 (AIAA paper no. 2007-4055).

Berry, Scott A., Chen, Fang-Jenq, Wilder, Michael C. and Reda, Daniel C. 2007 Boundary layer transition experiments in support of the hypersonics program. Proceedings of the 39th AIAA Thermophysics Conference, Miami, FL, June 25-28 (AIAA paper no. 2007-4266).

Bose, D., Wright, M. J., Bogdanoff, D. W., Raiche, G. A. and Allen, Jr., G. A. 2006 Modeling and experimental assessment of cn radiation behind a strong shock wave. J. Thermophys. Heat Transfer 20(2), 220-230.

Boyd, Iain D., Zhong, J., Levin, Deborah A. and Jenniskens, P. 2008 Flow and radiation analyses for stardust entry at high altitude. In: Proceedings of the 46th AIAA Aerospace Sciences Meeting and Exhibition, Reno, Nevada, 7-10 January (AIAA paper no. 2008-1215), pp. 1-34.

Braun, Robert D. and Manning, Robert M. 2007 Mars exploration entry, descent, and landing challenges. $J$. Spacecr. Rockets 44(2), 310-323.

Chauveau, S., Perrin, M.-Y., Rivière, P. and Soufiani, A. 2002 Contributions of diatomic molecular electronic systems to heated air radiation. J. Quant. Spectrosc. Radiat. Transfer 72(4), 503-530.

Colonna, G., Pietanza, L. D. and Capitelli, M. 2007 Macroscopic rates with vibrational non-equilibrium for $\mathrm{n} 2$ dissociation. Proceedings of the 39th AIAA Thermophysics Conference, Miami, FL, June 25-28. (AIAA paper no. 2007-4554).

da Silva, M. Lino and Dudeck, M. 2006 Arrays of radiative transition probabilities for $\mathrm{CO}_{2} \mathrm{~N}_{2}$ plasmas. J. Quant. Spectrosc. Radiat. Transfer 102, 348-386.

da Silva, M. Lino, Sobbia, R. and Witasse, O. 2009 Radiative trail of the phoenix entry. (AIAA paper no. 2009-1032).

Fujita, K. and Abe, T. 1997 Spradian, structural package for radiatio analysis: theory and application. Techical Report no. 669 , ISAS, Kanagawa, Japan.

Gallis, Michael A., Bond, Ryan B. and Torczynski, John R. 2010 Assessment of collisional-energy-based models for atmospheric species reactions in hypersonic flows. $J$. Thermophys. Heat Transfer 24(2), 241-253.

Gökçen, T. 2007 N2-CH4-Ar chemical kinetic model for simulations of Titan atmospheric entry. J. Thermophys. Heat Transfer 21(1), 9-18.

Gupta, Roop N. 2000 Aerothermodynamic analysis of stardust sample return capsule with coupled radiation and ablation. J. Spacecr. Rockets 37(4), 507-514.
Hartung, L. C. 1994 Predicting radiative heat transfer in thermo-chemical non-equilibrium flow-fields: theor $y$ and user's manual for the Loran code. Technical Report no. VA 23681-0001, NASA Langley Research Center, Hampton, VA, USA.

Huber, K. P. and Herzberg, G. 2010 Constants of diatomic molecules. In: NIST Chemistry WebBook, NIST Standard Reference Database Number 69 (ed. P. J. Linstrom and W. G. Mallard). Gaithersburg, MD: National Institute of Standards and Technology, http://webbook.nist.gov (retrieved May 8, 2010).

Hyun, S.-Y. 2009 Radiation code SPRADIAN07 and its applications. PhD thesis, School of Mechanical, Aerospace and Systems Engineering, Division of Aerospace Engineering, KAIST.

Johnston, Christopher O. 2006 Non-equilibrium shock-layer radiative heating for earth and Titan entry. PhD thesis, Virginia Polytechnic Institute and State University, Blacksburg, VA.

Kuznetsova, L. A. and Surzhikov, S. T. 1999 Absorption cross sections of diatomic molecules for problems of radiative heat transfer in low-temperature plasma. High Temp. 37(3), 348-358.

Laux, C. O. 2002 Radiation and non-equilibrium collisionalradiative models. In: VKI Special Course on PhysicoChemical Models for High Enthalpy and Plasma Flows Modeling (eds. D. Fletcher, J. M. Charbonnier, G. S. R. Sarma, and T. Magin) Rhode-Saint-Genèse, Belgium, June 4-7.

Leyland, P., Sobbia, R. and Voss, J. B. 2007 Chemical kinetic and radiating species studies of Titan aerocapture entry. In: Peter Jacobs, Tim McIntyre, Matthew Cleary, David Buttsworth, David Mee, Rose Clements, Richard Morgan and Charles Lemckert, 16th Australasian Fluid Mechanics Conference (AFMC), http://www.mech.uq.edu.au/ 16afmc/index.php.Gold Coast, Queensland, Australia, December 3-7, 497-502.

Magin, T. E., Caillault, L. A., Bourdon, A. and Laux, C. O. 2006 Nonequilibrium radiative heat flux modeling for the huygens entry probe. J. Geophys Res-planet 111, E07S12.

Mazoue, F. \& Marraffa, L. 2005 Flow-field/radiation coupling analysis for huygens probe entry into Titan atmosphere. In: Proceedings of the 38th AIAA Thermophysics Conference (AIAA paper no. 2005-5392) eISBN:978-1-62410-061-1.

McBride, B. J. and Gordon, S. 1996 Computer program for calculation of complex chemical equilibrium compositions and applications. Part 2: Users manual and program description. NASA Reference Publication 1311, June 1996.

Mitcheltree, R. A. and Gnoflo, E. A. 1995 Wake flow about the mars pathfinder entry vehicle. J. Spacecraft Rockets 32(5), 771-776.

Modest, M. F. 2003 Radiative Heat Transfer, 2nd edn. London: Academic Press.

Nelson, H. F., Park, C. and Whiting, E. E. 1991 Titan atmospheric composition by hypervelocity shocklayer analysis. J. Thermophys Heat Transfer 5(2), 157165.

Olejniczak, J., Prabhu, D., Bose, D. and Wright, M. J. 2004 Aeroheating analysis for the after body of a Titan probe. In: Proceedings of the 42nd AIAA Aerospace Sciences Meeting and Exhibition (AIAA paper no. 2004-0486) eISBN:978-1-62410-078-9.

Olejniczak, J., Wright, M. J., Prabhu, D., Takashima, N., Hollis, B. R., Zoby, E. V. and Sutton, K. 2003 An analysis of the 
radiative heating environment for aerocapture at Titan. (AIAA paper no. 2003-4953).

Osawa, H., Matsuyama, S., Ohnishi, N., Furudate, M. and Sawada, K. 2008 Numerical computation of radiative heating environment for huygens probe entry flight. $J$. Thermophys. Heat Transfer 22(2), 140-149.

Osawa, H., Matsuyama, S., Ohnishi, N. and Sawada, K. 2006 Comparative computation of radiative heating environment for Huygens probe entry flight. (AIAA paper no. 2006-3772)

Panesi, M., Babou, Y. and Chazot, O. 2008 Predictions of nonequilibrium radiation: analysis and comparison with east experiments. (AIAA paper no. 2008-3812).

Park, C. 1985 Non-equilibrium air radiation (neqair) program. Technical Report no. N85-30780, NASA, Washington, DC.

Park, C. 2007 Calculation of stagnation-point heating rates associated with stardust vehicle. J. Spacecraft Rockets 44(1), 24-32.

Park, C. S., Bershader, D. and Park, C. 1996 Radiative emission from the simulated shock layer of huygens probe. $J$. Thermophys Heat Transfer 10(4), 563-569.

Passarinho, P. and da Silva, M. Lino 2006 Gprd, a database for spectral properties of diatomic molecules of atmospheric interest. J. Mol. Spectrosc. 236(1), 148-149.

Playez, M., Vancrayenest, B. Fletcher, M. E. and Zuber D. G. 2004 Titan atmosphere plasma investigation using spectroscopic techniques. Proceedings of the Fifth European Symposium on Aerothermodynamics for Space Vehicles (ESA paper no. SP-563).
Potter, D. 2011 Modelling of radiating shock layers for atmospheric entry at earth and mars. PhD thesis, School of Mechanical and Mining Engineering, University of Queensland, Australia.

Savajano, R., Sobbia, R., Gaffuri, M. and Leyland, P. Submitted. Reduced chemical kinetic model for Titan entries. International Journal of Chemical Engineering. Volume 2011 (2011), Article ID 970247.

Smith, A., Wood, A., Dubois, J., Fertig, M. and Pfeiffer, B. 2006 Plasma radiation database parade v22 final report. Technical Report no. ESTEC contract 11148/94/NL/FG, FGE TR28/96, ESA ESTEC.

Whiting, Ellis E., Park, C., Liu, Y., Arnold, James O. and Paterson, John A. 1996 Neqair96, non-equilibrium and equilibrium radiative transport and spectra program: user's manual. Technical Report no. 1389, NASA, Washington, DC.

Witasse, O., da Silva, M. Lino, Sobbia, R., Leyland, P., Marraffa, L., Schmitz, P., Denis, M., del Rio, J. Diaz, Neukum, G., Hoffmann, H., et al. 2012 Mars express observation of the phoenix mars entry, part i: intensity predictions, results, and lessons learned. CEAS Space Journal.

Wright, M. J., Bose, D. and Olejniczak, J. 2004 The impact of flowfield-radiation coupling on aeroheating for Titan aerocapture. (AIAA paper no. 2004-0484).

Zel'dovich, Ya. B., Raizer, Yu. P., Hayes, Wallace D. and Probstein, Ronald F. 1966 Physics of Shock Waves and High-Temperature hydrodynamic Phenomena. Waltham, MA: Academic Press. 